\title{
Los salarios en México como factor de competencia desleal en la industria automotriz, 2003-2019
}

Agustin Tapia Alba *

Cesaire Chiatchoua ${ }^{* *}$

\section{Resumen}

$\mathrm{C}^{\text {lobjetivo de este artículo es analizar el nivel de los salarios }}$ implementados en México en el sector automotor en comparación con sus dos socios comerciales en América del Norte como factor de competencia desleal en el sector automotor. Mediante una metodología descriptiva y documental, así como el uso de datos del INEGI, 2018 y el Automotive Average Salaries, 2020. Los resultados muestran que México tiene el salario más bajo: 1,350 dólares/mensual; comparado a los Estados Unidos 6,566.66 y Canadá 9, 585.85. Finalmente, México para lograr la competitividad del sector automotor debe no solo revisar su política salarial al alza, sino, también enfocarse en desarrollar los factores que impulsen la productividad como la innovación, la calificación de la mano de obra, la seguridad pública y las condiciones macroeconómicas.

* Universidad Popular Autónoma del Estado de Puebla. Doctorado en Estudios Sociales por la Universidad Autónoma Metropolitana, México. Actualmente es Profesor - Investigador en la Universidad Popular Autónoma del Estado de Puebla, Facultad de Negocios Internacionales Logística Internacional. Finalmente, sus líneas de investigación son; Comercio Internacional y Desarrollo Económico. jtapiaalba@gmail. com. ORCID: 0000-0002-5911-7209.

** Universidad La Salle México. Doctorado en Ciencias Económicas por la Escuela Superior de Economía del Instituto Politécnico Nacional, México. Actualmente pertenece al SNI nivel 1 es Profesor - Investigador en la Universidad La Salle México, Facultad de Negocios y responsable del proyecto. Finalmente, sus líneas de investigación son; Comercio Internacional, Inversión Extranjera Directa, Administración de las MyPES como también Desarrollo Económico. cesaire.chiatchoua@lasalle.mx. ORCID: 0000-0001-8915-7562. 


\author{
Palabras clave \\ Productividad, salarios, inversión, innovación, especialización. \\ Fecha de recepción: \\ Marzo de 2020 \\ Fecha de aceptación: \\ junio de 2020

\section{Wages in Mexico as a factor of unfair competition in the automotive industry, 2003-2019} \\ Key words \\ Productivity, salaries, investment, innovation and specialization. \\ Final submission: \\ March 2020 \\ Acceptance: \\ June 2020
}

\title{
Abstract:
}

The main goal of this paper is to analyse the status of the salaries paid in Mexico in its car industry and compare them against those paid in both Canada and the United States. We will use a descriptive and documentary methodology, data provided by INEGI on 2018 and Automotive Salaries databases are taken in count. Evidence shows that, not surprisingly, that Mexican workers receive the lowest salaries in North America. Mexico pays $\$ 1,350.00$ a month while Canadian workers make $\$ 9,585.85$ dollars a month. Mexico should increase their salaries in order to prompt productivity and stimulate competitiveness. The country also should promote better conditions in terms of public security, innovation conditions and macroeconomic environment.

\section{Introducción}

La importancia de la industria automotriz en el desarrollo industrializador de México es considerable si se toma en cuenta la diversidad de actividades y sectores relacionados con ésta. Proveedores de diversos tipos de componentes e insumos que se requieren para fabricar un automóvil pueden ilustrar la relevancia y complejidad relacionada con el funcionamiento de esta industria en el entorno económico actual. Asimismo, también se puede apreciar el esfuerzo que los gobiernos de los países pueden hacer para intentar desarrollar políticas públicas que busquen desarrollar esta industria en sus países. 
México es uno de los países con mayor exportación de automóviles. En 1993 el sector representaba, a pesos constantes 2013, menos de 200 mil millones de pesos. En la actualidad, representa más de 400 mil millones. ${ }^{1}$ En el 2018, las exportaciones de autos mexicanos repuntaron $19 \%$ comparado al año anterior; es decir, casi 50, 000 millones de dólares. En una década nuestro país rebasó también a Francia, Bélgica, España y Corea del Sur. Una de las razones de esto se debe a que las armadoras que se han instalado en México se caracterizan por los bajos salarios. ${ }^{2}$

Esta situación salarial en México en esta industria fue objeto de atención por parte de autoridades y sindicatos en Estados Unidos y, principalmente, Canadá en el marco de la renegociación del Tratado de Libre Comercio de América del Norte (TLCAN), debido a los reclamos de aquellos que sostienen que México sustituye variables tales como la inversión en infraestructura, educación y mejoramiento de la seguridad pública con el pago de salarios bajos para atraer inversiones en el marco del acceso preferencial al mercado de la región. A partir de lo anterior, se establece que representan una práctica desleal en materia de comercio.

Para llevar a cabo esta investigación se siguieron varias estrategias metodológicas. De acuerdo al ámbito y al diseño bibliográfico o documental de la investigación, se utilizaron fuentes de información secundarias u otras investigaciones, ya que se pretende profundizar y ampliar el conocimiento sobre la situación prevalente en materia salarial en la industria automotriz mexicana. Se realizó una revisión bibliográfica exhaustiva y actualizada, sobre los informes de las estadísticas oficiales en torno a la fuerza de trabajo en la industria automotriz y documentos sobre el mercado salarial en México y algunos otros países. Una vez realizada

\footnotetext{
1 INEGI, Colección de Estudios Sectoriales y Regionales. Conociendo la industria automotriz. INEGI, 2018, http://internet.contenidos.inegi.org.mx/contenidos/Productos/ prod_serv/contenidos/espanol/bvinegi/productos/nueva_estruc/702825106829.pdf (Consultado el 12-2-2020).

2 Roberto Morales. "México escala al cuarto sitio en exportación de autos". El Economista. 26 de marzo de 2019, https://www.eleconomista.com.mx/empresas/Mexico-escala-al-cuarto-sitio-en-exportacion-de-autos-20190326-0158.html. (Consultado el 12-2-2020).
} 
la revisión bibliográfica se procedió a interrelacionar la información obtenida para analizarla y reflexionar, así como deducir la presentación adecuada de las variables objeto de estudio, lo que se expondrá a continuación, después de desarrollar algunos antecedentes de la industria automotriz en México.

\section{Antecedentes de la industria automotriz en México}

Aun cuando México no se encontraba entre los principales fabricantes de autos al inicio de esta industria, a finales del siglo XIX los gobiernos mexicanos de la época comenzaron a hacer esfuerzos por atraer empresas. De inicio, el país se enfocó en inversionistas estadounidenses para que construyeran plantas armadoras. Las primeras armadoras al país en 1921 cuando se estableció la ensambladora Buick y posteriormente la planta Ford en 1925. Una década después se localizó también la firma General Motors en 1935, seguida por Chrysler (Fábricas Automex) en 1938. ${ }^{3}$

La experiencia mexicana en materia de proteccionismo a la industria automotriz durante el periodo de sustitución de importaciones fue destacada. En primer lugar, se creó la empresa Vehículos Automotores Mexicanos (VAM), la cual fue producto de la coinversión entre el gobierno mexicano y American Motors, ${ }^{4}$ que funcionó entre los años sesenta y ochenta y fue disuelta en 1988. Otro caso de coinversión del gobierno mexicano en el sector automotor lo representó la formación de Dina-Renault.

Ambos intentos del gobierno mexicano, tanto VAM como Dina-Renault, pueden considerarse como medianamente exitosos, pues se puede apreciar una falta de interés de los inversionistas mexicanos en participar en el sector, ya sea de forma individual o en combinación con el sector público. Lo anterior a pesar de lo que establecía un Decreto presidencial que databa de 1962 mis-

\footnotetext{
3 Jaime Linares Zarco "El espacio de los salarios y de los robots en la industria automotriz en México”. Dinámica Económica y Procesos de Innovación en el Desarrollo Regional. (México: Asociación Mexicana de Ciencias para el Desarrollo Regional A.C y UNAM, 2018), 168- 189.

4 Ibíd.
} 
mo que pretendía que las empresas mexicanas fabricaran vehículos automotores y no sólo componentes o refacciones.

A la luz de lo ocurrido se puede afirmar que ese instrumento fracasó en su intento, ya que la inversión privada de origen mexicano prácticamente no se tradujo en el financiamiento y operación de plantas armadores de autos en el país. La inversión privada de origen local se concentró en el sector de las autopartes. ${ }^{5}$

En 1969 el gobierno lanzó otro decreto que tenía la intención de fomentar las exportaciones del sector automotor. Éste ordenaba a las empresas que operaban en México que exportaran bienes por al menos el mismo valor de las importaciones que hacían de autos y componentes. El resultado de dicha medida fue parcial, ya que las exportaciones de la industria representaban el 16\% de las importaciones. Lo anterior se explicaba por el hecho de que la industria operaba con maquinaria obsoleta y tenía acaparado el mercado local debido a un decreto previo, de 1962, que prohibía a las empresas y ciudadanos mexicanos importar autos, lo cual eliminó cualquier intento modernizador de la industria.

A pesar de lo anterior, el panorama de la industria automotriz registra cambios importantes a partir de la crisis económica que transforma al sistema político en México. 1982 representa un cambio de tendencias muy importante ya que la devaluación del peso mexicano en ese año provocó que las empresas fabricantes de autopartes tuvieran precios más bajos para los productos que vendían y de esa forma, aumentará su competitividad en el exterior. A esto debe anotarse el ingreso de México al GATT en 1986 y los cambios hechos a su legislación. Se reforma la Ley Aduanera y se crea la Ley de Comercio Exterior.

En 1994 se firma el TLCAN, instrumento clave que contribuyó a maximizar la ventaja comparativa de México en el ámbito comercial debido al acceso preferencial que ese instrumento les dio a las empresas que decidieran instalarse en el país para fabri-

5 Karen Ochoa Valladolid. "México y la cuena del Pacífico". Análisis. La industria automotriz de México: las expectativas de competitividad del sector de autopartes. No. 26 (2005): 33-58. 
car mercancías que serían posteriormente exportadas al mercado estadounidense y canadiense. La estratégica ubicación geográfica se combinaba con el acceso preferencial a esos mercados y de esa forma, México comenzó a poner las bases que permitirían ubicar al país entre los principales exportadores de automóviles y autopartes del mundo.

\section{La ventaja comparativa implementada en el caso de México} Hay que recordar que la industria automotriz debería evolucionar bajo los principios propuestos por la Teoría de la División Internacional del Trabajo y la Ventaja Comparativa, que, en esencia, los factores que determinan la localización de inversiones en el sector automotor en el área de Norteamérica, debería radicar en las diferencias de productividad y disponibilidad de factores de producción, incluyendo de forma principal condiciones de infraestructura y seguridad pública, en cada uno de los tres países de la región y no sólo considerar la carta de bajos salarios para decidir la ubicación, como Krugman ilustra en el argumento de los salarios paupérrimos. ${ }^{6}$

La Teoría de la División Internacional del Trabajo implica que la especialización es la base de la formación de ventajas comparativas de forma tal que los costos de los factores productivos tenderán a igualarse en tanto mayor sea la especialización que haya en una industria. Parece ser que por el alto grado de integración de las cadenas de valor dentro del sector automotor refuerzan lo propuesto por esta teoría. Sin embargo, aun con la creciente integración de las operaciones de la empresa, Supply Chain Management, la cual es definida como un estilo organizacional más que como el flujo de materiales en la organización ${ }^{7}$ existente en el sector, existen diferencias en los salarios pagados en los mismos puestos en diferentes países del mundo.

6 Paul Krugman and Maurice Obstfeld. Economia Internacional Teoria y Politica. (Estados Unidos: Pearson: 2006), 4.

7 Gene Tyndall, et al. Supercharging Supply Chains: New Ways to Increase Value Through Global Operational Excellence. (Nueva York: John Wiley \& Sons, 1998). 
La decisión de los gobiernos mexicanos en el sentido de buscar mayor inversión directa en el sector automotor usando el argumento de los salarios es incorrecto si consideramos la posición geográfica del país. Es suficiente ventaja la ubicación geográfica de México con relación al mercado estadounidense, por lo cual no deberían sumarse incentivos adicionales para atraer empresas al país.

En concordancia con el Modelo Gravitacional de Comercio en el caso mexicano, su ubicación estratégica y un conjunto de factores económicos, políticos y condiciones adecuadas de infraestructura y seguridad pública serían suficientes para fomentar la competitividad del país y, por tanto, atraer empresas a invertir en el diseño y fabricación de automóviles.

De acuerdo con el mencionado modelo, la posición geográfica de México es el factor que determina la ventaja comparativa del país ya que la cercanía que tiene el país con relación al mercado de consumo más importantes del mundo, EUA, permite que las exportaciones mexicanas puedan entregarse en menor tiempo y con menores costos de transportación en comparación con aquellos exportadores que quieran vender sus productos en los Estados Unidos. La ubicación estratégica de México es el factor más importante que se evalúa cuando el país suscribe un Acuerdo de Libre Comercio.

\section{Situación salarial en la industria automotriz en México en el Siglo XXI}

\subsection{El dilema del aumento salarial en el sector automotor}

Hay que destacar que en México existen dos tipos de fabricantes relacionados con la industria automotriz; a saber, las armadoras de autos y camiones, y los fabricantes de autopartes. Es relevante señalar lo anterior, ya que estas dos industrias tienen niveles salariales distintos. Las primeras pagan más a sus trabajadores en comparación con los fabricantes de autopartes y refacciones.

Al respecto, el Centro de Estudios Económicos del Sector Privado (CEESP) afirma que: 
92 Los SALARIOS EN MÉxiCo COMO FACTOR DE COMPETENCIA DESLEAL EN LA INDUSTRIA AUtomotriz, 2003-2019 / Agustin Tapia Alba, Cesaire Chiatchoua

Dentro del entorno actual de debilidad de la economía, un aumento significativo al salario resta competitividad a la planta productiva en razón de que es difícil que aumente la productividad laboral en un entorno de desaceleración. De considerarse un aumento al salario muy sustantivo podría inclusive afectar el nivel de empleo, sobre todo en el sector formal, SIC. ${ }^{8}$

\section{Imagen 1: Aportación de diversos sectores industriales en el PIB mexicano}

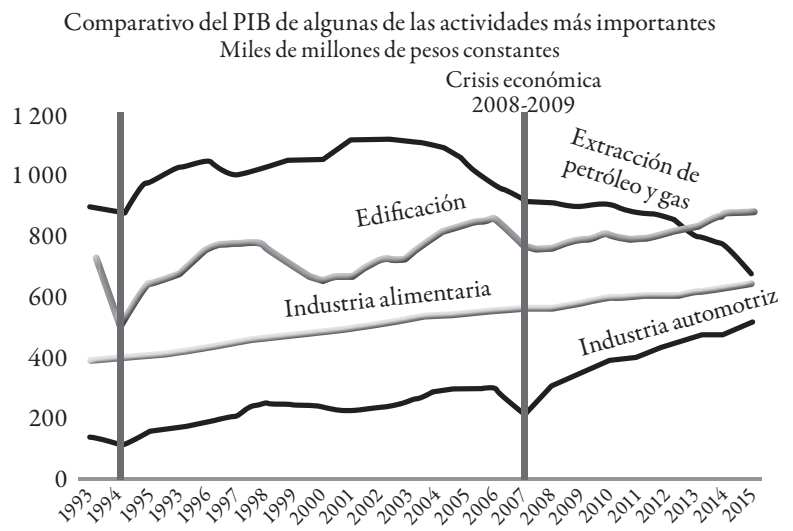

Fuente: INEGI. Sistema de Cuentas Nacionales 2013.

En dos décadas, la industria automotriz creció más del 5\% anual en promedio, mientras que la economía en su conjunto lo hacía en menos de 3\%. Lo mismo puede afirmarse en el caso de la contribución del sector en materia de empleo formal en el conjunto de las industrias manufactureras en el país. En 2007 los trabajadores automotrices representaban 15\% del total de la industria; en 2017 ya eran $22 \%$.

Lo señalado en el estudio del INEGI contradice lo señalado por el CEESP, la industria automotriz crece más que el conjunto de la economía mexicana y aumenta su contribución, también, en relación al personal ocupado de la industria manufacturera nacional. De esa forma, es lógico suponer que la evolución de los salarios en el sector debiera seguir la misma tendencia que presenta el sector en materia de valor económico y contribución del empleo 
manufacturero, ya que el crecimiento del valor del sector y el empleo formal es producto de un aumento de productividad de la industria automotriz.

En ese sentido, el aumento de la productividad en el sector automotor, es de destacar que las empresas de la industria han digitalizado buena parte de sus productos con lo que han registrado un aumento de la productividad hasta de $25 \%$. ${ }^{9}$ El citado aumento de productividad se explica en el uso más eficiente de los insumos que hace la industria y el incremento de los niveles de capacitación de los trabajadores; es decir, si la productividad sube, la contribución del sector automotor lo hace de la misma forma, la pregunta que corresponde hacernos es ¿cómo se han comportado los salarios de esa industria?

\subsection{Evolución de los salarios en la industria automotriz}

Como se puede apreciar en el cuadro 1 , los salarios en el periodo estudiado no han tenido el mismo crecimiento en comparación con el aumento de la productividad, contribución al PIB y empleo en el sector manufacturero. Es conveniente señalar que: "Resulta significativo que los días de salario mínimo en la industria automotriz, no son bajos. El promedio total es de 4.5 días, equivalente a un sueldo de \$ 5,971.00 mensuales; al desglosarlo, las ensambladoras tienen 9.9 veces de salario mínimo, es decir un salario mensual de $\$ 13,136.00$. En las plantas de autopartes baja el salario mensual promedio a $\$ 5,460.00$, que no parece indecoroso." ${ }^{10}$

\section{Cuadro 1. Evolución salarial en la industria automotriz} en México 2003-2008 (Salarios Mínimos)

\begin{tabular}{|c|c|c|}
\hline & 2003 & 2008 \\
\hline Autos y camiones & 9.9 & 8.9 \\
\hline Auto partes & 4.1 & 4.1 \\
\hline
\end{tabular}

Fuente: Sueldos y salarios de la industria automotriz en México en 2003 y 2008 : Aguascalientes, Estado de México, Puebla, Chihuahua y Coahuila de Zaragoza.

El cuadro 2 muestra la evolución de los salarios. A pesar de la aparente evolución salarial dentro de la industria automotriz en Mé- 
xico, por ejemplo, en 2007 el pago promedio dentro de la industria armadora de autos era de $\$ 19,175$ y en 2017 ascendió a $\$ 23,842$, si se toma en cuenta el impacto inflacionario en el periodo, $5.3 \%{ }^{11}$ según Banco de México, se aprecia en la figura 1 que el equivalente en salarios mínimos de acuerdo con el INEGI era de: "9.9 veces el salario mínimo para los fabricantes de autos y camiones y 4.8 veces el salario mínimo para los fabricantes de autopartes en $2017{ }^{\prime 12}$

Cuadro 2. Evolución de salarios en la industria automotriz en México, 2007-2017

\begin{tabular}{|l|c|c|c|c|c|c|c|c|c|c|c|}
\hline & 2007 & 2008 & 2009 & 2010 & 2011 & 2012 & 2013 & 2014 & 2015 & $\mathbf{2 0 1 6}$ & $\mathbf{2 0 1 7}$ \\
\hline $\begin{array}{l}\text { Fabricación de } \\
\text { automóvilesy } \\
\text { camiones }\end{array}$ & 19,175 & 21,339 & 21,290 & 21,059 & 21,673 & 21,368 & 21,398 & 20,840 & 21,768 & 22,428 & 23,842 \\
\hline $\begin{array}{l}\text { Fabricación de } \\
\text { autopartes }\end{array}$ & 8,169 & 8,441 & 8,565 & 8,530 & 8,420 & 8,523 & 8,806 & 9,257 & 10,015 & 10916 & 11,505 \\
\hline
\end{tabular}

Fuente: INEGI, 2018

Figura 1. Evolución de la Tasa Inflacionaria en México, 2007-2017 INCP: Inflación general, subyacente y no subyacente Porcentajes De Ene 21,2007 Hasta Dic 01,2017

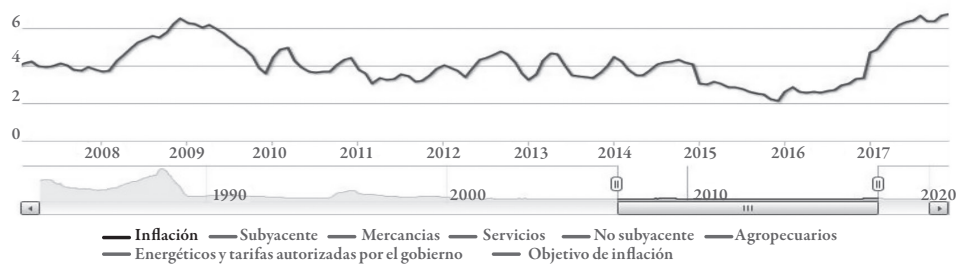

Entonces, los aumentos salariales registrados en la industria automotriz sólo han podido compensar el impacto de la inflación sobre la economía en general (véase figura 1). En realidad, no ha habido mejoras sustanciales para los trabajadores del sector, la razón que justifique la diferencia de más de 2.3 veces el salario que ganan los trabajadores de las armadoras de autos y los que perciben los fabricantes de autopartes. Quizá un argumento que lo explique es la mayor fuerza de los sindicatos de las plantas armadores en comparación con aquellos que operan en las plantas de autopartes.

\footnotetext{
${ }^{11}$ Estos resultados son con base en el Banco de México. Sistema de Información Económica [Nota de los autores].
}

12 Op. Cit., INEGI. 
Por otra parte, el cuadro 3, muestra los salarios promedio en distintos países. México presenta el salario más bajo, además, las diferencias son notables con relación a cualquiera de los países analizados. Lo anterior se justifica, según organismos como el CEESP, debido a la menor productividad de la mano de obra mexicana en comparación con la de otros países;

Cuadro 3. Comparación salarial promedio por puesto en la industria automotriz en distintos países en 2020. (Salario mensual y cantidades en USD)

\begin{tabular}{|c|c|c|c|c|c|c|c|c|}
\hline Puesto & Alemania & Brasil $^{13}$ & Canadá $^{14}$ & China & $\begin{array}{c}\text { Estados } \\
\text { Unidos }^{15}\end{array}$ & Japón & México & $\begin{array}{c}\text { Reino } \\
\text { Unido }^{16}\end{array}$ \\
\hline $\begin{array}{c}\text { Gerente de } \\
\text { ensamblado }\end{array}$ & $11,445.70$ & $2,611.94$ & $9,585.85$ & $4,028.94$ & $6,566.66$ & $8,725.42$ & $1,350.61$ & $12,318.19$ \\
\hline $\begin{array}{c}\text { Eléctrico- } \\
\text { automotriz }\end{array}$ & $6,230.32$ & $1,553.42$ & $5,224.70$ & $2,100.19$ & $3,900.00$ & $4,801.24$ & 710.28 & 5,300 \\
\hline $\begin{array}{c}\text { Técnico } \\
\text { automotriz }\end{array}$ & $6,446.32$ & $1,592.37$ & 5798.09 & $2,243.06$ & $3,950.00$ & $5,271.42$ & 721.43 & $5,325.00$ \\
\hline $\begin{array}{c}\text { Ingeniero de } \\
\text { pruebas }\end{array}$ & $11,337.00$ & $2,749.41$ & $10,261.30$ & $3,757.09$ & $6,841.66$ & $9,313.50$ & $1,350.64$ & $9,583.33$ \\
\hline $\begin{array}{c}\text { Mecánico } \\
\text { automotriz }\end{array}$ & $6,295.15$ & $1,530.51$ & $5,508.00$ & $2,300.21$ & $3,891.66$ & $5,126.75$ & 753.32 & $5,258.33$ \\
\hline Soldador & $5,593.19$ & $1,347.20$ & $4,752.55$ & $1,900.18$ & $3,391.66$ & $4,381.55$ & 656.43 & $5,888.44$ \\
\hline $\begin{array}{c}\text { Gerente de } \\
\text { autopartes }\end{array}$ & $12,093.60$ & $3,093.90$ & $11,520.60$ & $4,214.68$ & $7,300.00$ & $9,946.07$ & $1,442.09$ & $13,875.00$ \\
\hline
\end{tabular}

Fuente: Automotive Average Salaries 2020. ${ }^{17}$

En México los salarios son bajos debido a la baja productividad de los trabajadores del país. Por lo que, si queremos ver aumentos de salario considerables, primero debe aumentar la productividad. Sin embargo, ni en el sector automotor o ningún otro. los líderes empresariales o los representantes del gobierno se han tomado a la tarea de precisar de cuánto esperar en materia del incremento del uno con relación a la otra.

\footnotetext{
${ }^{13}$ El sitio web proporciona el dato de salarios en Sao Paulo [nota de los autores].

${ }^{14} \mathrm{El}$ sitio web presenta el salario anual. Se divide el mismo entre 12 meses. [nota de los autores].

${ }^{15}$ El sitio web presenta el salario anual. Se divide el mismo entre 12 meses. [nota de los autores].

${ }^{16} \mathrm{El}$ sitio web presenta el salario anual. Se divide el mismo entre 12 meses. [nota de los autores].

${ }^{17}$ En todos los casos, excepto Estados Unidos, los salarios se indican en la moneda local, por lo cual se hace la conversión a USD, al utilizar la herramienta de conversión de divisas OANDA.com. Tipos de cambio al 19 de febrero 2020 [nota de los autores].
} 
Al revisar el indicador Labour Productivity Forecast (Pronóstico de Productividad Laboral) definido como una relación existente entre el PIB de un país por hora trabajada por sus habitantes y publicado por la OCDE. Según el organismo, ese indicador es adecuado usarlo para medir la productividad de una economía debido a que califica el uso de los factores productivos en lugar de solo medir la cantidad de trabajo producido, considera la productividad con horas trabajadas. La información se expresa en el promedio de horas trabajadas multiplicadas por el dato de empleo correspondiente en cada país. Esta relación se expresa por un índice con base $2010=1^{18}$ podemos encontrar lo siguiente:

Cuadro 4. Pronóstico de Productividad Laboral

en Norteamérica 2021. ${ }^{19}$

\begin{tabular}{|c|c|}
\hline \multicolumn{2}{|c|}{ Pronóstico de Productividad Laboral según OCDE } \\
\hline Canadá & 1.032 \\
\hline Estados Unidos & 1.059 \\
\hline México & 0.987 \\
\hline
\end{tabular}

De acuerdo con el cuadro 4, la productividad en México es menor comparado a los países del norte. De hecho, México se ubicó en el penúltimo lugar de en este indicador según la OCDE. Asimismo, este indicador nos revela un dato esclarecedor en cuanto a la relación que tiene la productividad con los salarios. A diferencia de lo que sostiene el CEESP, primero deben aumentar los salarios para que lo haga de la misma forma la productividad. Hay que recordar que el pago de salarios se da después de que se llevó a cabo el trabajo que produjo bienes y servicios, mientras que los otros factores productivos son pagados antes de usarlos en los procesos productivos.

México debe reconsiderar su política de bajos salarios y, en su lugar, debe aumentar su competitividad en la economía a nivel general. El país debe invertir en educación desarrollo de infraes-

${ }^{18}$ OCDE. Labour productivity forecast. OCDE. https://data.oecd.org/lprdty/labour-productivity-forecast.htm\#indicator-chart. (Consultado el 22-2-2020).

19 Ibid. 
tructura eficiente, mejorar sus estándares laborales, así como cuidar de su medio ambiente. Todo lo anterior debe hacerse pronto, ya que, en el caso de la industria automotriz, el país está cerca de llegar a su máximo potencial en cuanto a la producción de automóviles, lo anterior puede ocurrir tan pronto como 2022. Para demostrar lo anterior, se puede afirmar que el constante aumento de la producción de autos en México puede llegar a su límite en poco tiempo, aquí la evidencia a manera de gráfica:

Figura 2. Relación entre producción de automóviles y la capacidad de producción México

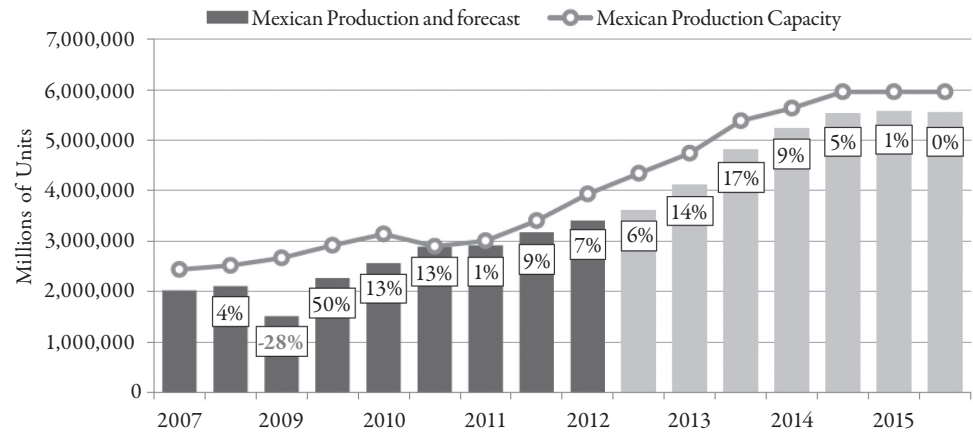

Sources: LMC Automotive

Note: Percentages represent year-over-year changes in Mexican production ang forecast numbers.

Fuente: LMC Automotive.

\section{Competencia desleal mexicana en el sector automotor}

Como se ha podido observar, México ha empleado una política de bajos salarios. La misma ha sido defendida y propuesta por los líderes empresariales y las últimas administraciones. La misma tiene el objetivo de convencer a las empresas armadoras de automóviles y autopartes para que ubiquen sus plantas en el país. El resultado de esa decisión ha convertido al país en uno de los principales fabricantes de autos y autopartes. Asimismo, las empresas que se han reubicado en el país han recibido estímulos fiscales y administrativos.

La decisión de reubicar plantas en México ha provocado que Canadá y Estados Unidos hayan perdido miles de puestos labo- 
rales en el sector automotor y que, esos empleos se muden a México. Esto ha provocado que algunos sectores sociales y laborales en aquellos países identifiquen al nuestro como un competidor desleal que prefiere pagar salarios muy bajos a sus trabajadores con el objetivo de atraer empleos. Debido a lo anterior surge la necesidad de renegociación del TLCAN, los gobiernos canadiense y estadounidense pusieron como una de las condiciones a nuestro país, que los salarios en la industria subieran a 16 dólares por hora. ${ }^{20}$

La política implantada por México, y analizada anteriormente se puede calificar como Dumping Social, esto implica que las condiciones salariales y laborales de los trabajadores mexicanos sean inferiores en comparación con otros países no importando cómo evolucione la productividad del trabajador. Entre 2007 y 2015, los trabajadores mexicanos han incrementado sus niveles de productividad en 9\% al año. En contraste, como se anotó previamente, los salarios de los trabajadores no se han modificado en el periodo. ${ }^{21}$ Lo anterior rompe la lógica de los organismos empresariales.

México practica un comercio desleal e injusto, con relación a los otros países norteamericanos, en el sector automototr debido a que los bajos salarios pagados en el país representan el único incentivo para trasladar plantas automotrices de Canadá y Estados Unidos a México. Lo que lo hace menos competitivo, más inseguro, atrayendo menos inversión extranjera e invierte menos en otros países en comparación con nuestros socios comerciales.

Es difícil creer que un país con el potencial y acuerdos comerciales que tiene México, y en especial su posición geográfica, prefiera sacrificar el bienestar de sus trabajadores y ciudadanos en lugar de hacer las inversiones requeridas para mejorar su perfil competitivo. De acuerdo con la evidencia, el sector automotor

\footnotetext{
${ }^{20}$ Joan Byrden. "NAFTA: Canada pushes for enforceable, progressive labour standards. Maclean's". The Canadian Press. (26 de septiembre 2017), https://www. macleans.ca/economy/nafta-canada-pushes-for-enforceable-progressive-labour-standards/ (Consultado el 22-2-2020).

${ }^{21}$ Alex Covarrubias. "Mexico competitive advantage in NAFTA: A case of social dumping?” Norteamérica. Revista Académica del CISAN-UNAM, 14 (2019), http:// dx.doi.org/10.22201/cisan.24487228e.2019.1.340. (Consultado el 2-6-2020).
} 
mexicano se ha desarrollado sobre una perspectiva de corto plazo que puede hacer pagar al país un costo muy alto por no privilegiar una visión estratégica de largo plazo. No parece conveniente erosionar las condiciones de vida de la población local para conseguir una ventaja competitiva. Los trabajadores mexicanos reciben un salario mucho menor (ver cuadro 3 ) al de sus contrapartes canadiense y estadounidense.

En el marco de la renegociación del TLCAN, Canadá, principalmente, reclamaba que México debía incrementar los salarios de sus trabajadores debido a que estos han causado la pérdida de empleos, se calculan 55 mil, en el sector manufacturero de ese país. Un ejemplo de ello lo representa General Motors (GM), empresa que decidió reubicar una planta que producía SUV's en Ontario, Canadá a México por el argumento de los bajos salarios. Esta decisión le hace perder a Canadá cerca de mil puestos de trabajo bien remunerados. Puestos que en México tendrán salarios mucho menores. Lo anterior se complica si se toma en cuenta que los contribuyentes canadienses pagaron hasta 13.7 mil millones de dólares canadienses, en 2009, para rescatar a Chrysler y GM de la quiebra. ${ }^{22}$

En Estados Unidos la situación es más grave aún. Desde la firma del TLCAN, en 1994, el país ha perdido 840 mil empleos en el sector manufacturero. Los empleos de ese sector tienen salarios 30\% más altos que los correspondientes al sector servicios. ${ }^{23}$ La crisis de 2008 acentuó esa situación. Un año después, los empleos generados, sin embargo, tenían salarios hasta $25 \%$ menores en comparación con los empleos perdidos. En plantas automotrices de Alabama, Mississippi, Indiana, Ohio, Michigan e Illinois los salarios han caído hasta $24 \% .{ }^{24}$ En esencia, los nuevos empleos

\footnotetext{
22 Alexandra Posadzki and Paola Loriggio. "General Motors moving more than 600 jobs in Ontario to Mexico for cheaper labour: union”, Global News, (28 enero 2017). https://globalnews.ca/news/3209728/general-motors-to-cut-up-to-600-jobs-insouthwestern-ontario/ (Consultado el 26-2-2020).

${ }^{23}$ Roger Batra. The Myth of Free Trade. Nueva York: Simon \& Schuster, 1996.

${ }^{24}$ Catherine Ruckelshaus. "Manufacturing low pay: declining wages in the Jobs that built America's Middle Class", National Employment Law Project, (20 noviem-
} 
en el sector industriales no permiten a los trabajadores estadounidenses mejorar su nivel de vida en comparación con el pasado.

En la publicación citada, se consigna que actualmente el 14\% de los trabajadores de armadoras automotrices son contratados bajo esquemas de outsourcing o proveeduría y son empleos temporales. En esos casos, se esconde el hecho de que los salarios pagados por empresas de proveeduría son hasta $29 \%$ más bajos que los pagados por las empresas automotrices cuando estas contratan directamente a sus trabajadores. Además, de que salarios, de outsourcing y empleos temporales, no se incluyen en el cálculo del salario promedio pagado en la industria automotriz en los Estados Unidos. Hay que destacar que esta situación ha ido en aumento a partir de una mayor reubicación de plantas armadoras a México.

\section{Reflexiones finales}

Como se ha podido constatar, México ha empleado una política de dumping social en contra de sus propios trabajadores, esto con la intención de captar mayor IED, en específico en el sector automotor. El propósito señalado tiene como consecuencia que los salarios que se pagan en México sean los más bajos en relación a algunos países importantes en materia de producción y consumo de automóviles y autopartes en el mundo. Nos resulta difícil de creer que el gobierno y los sectores empresariales del país promuevan una política que no tiene muchos ganadores a largo plazo.

La experiencia mexicana y su relación con la industria automotriz debe ser estudiada con cuidado debido a que el país, y su política de bajos salarios, contradice los supuestos teóricos que señalan que la ubicación de inversiones se hace tomando en cuenta factores relacionados con la productividad, eficiencia, condiciones macroeconómicas, innovación, calificación de la mano de obra y seguridad pública. En su lugar, los factores que explican el éxito del país para atraer IED en el sector automotor son su ubicación geográfica y los bajos costos de produc-

bre 2014). https://www.nelp.org/publication/manufacturing-low-pay-decliningwages-in-the-jobs-that-built-americas-middle-class/ (Consultado el 25-2-2020). 
ción que implica tener los salarios, prácticamente, más bajos de la industria en el mundo.

Más allá de consideraciones nacionalistas, debemos reconocer que México ha aplicado un modelo de competencia desleal en la industria automotriz. Dicho modelo ha convertido a México en uno de los principales productores y exportadores de automóviles del mundo. En consecuencia, se espera que nuevas inversiones en el sector sigan teniendo como destino nuestro país. La consecuencia de ello es que las condiciones de bienestar de los trabajadores mexicanos no han mejorado en los últimos diecisiete años. Más aún, las condiciones laborales en Canadá y Estados Unidos han empeorado a partir de la puesta en marcha del TLCAN.

Habrá que dar el beneficio de la duda al T-MEC cuya entrada en vigor será el 1 de julio de 2020 y su impacto en las condiciones laborales de los trabajadores automotrices en los tres países para evaluar si las disposiciones sobre el aumento de salarios en México, requerido en el caso de los vehículos exportados a Estados Unidos y Canadá cumplen con el objetivo de reducir la deslealtad con la que México ha competido en los últimos años. Es deseable que así ocurra, debido a que eso permitiría generar mejores condiciones laborales y de vida en los tres países de Norteamérica.

\section{Fuentes}

Automotive average Salaries, http://www.salaryexplorer.com/ salary-survey.php?loc $=228 \&$ loctype $=1 \&$ job $=10 \&$ jobtype $=1 \&$ job2 $=21 \&$ jobtype $2=3$ survey.php?loc $=228 \&$ loctype $=1 \&$ job $=10 \&$ jobtype $=1 \&$ job2 $=21 \&$ jobtype $2=3$ (Consultado el 2 de junio de 2020).

Batra, Roger. The Myth of Free Trade. Nueva York: Simon \& Schuster, 1996.

Byrden, Joan. "NAFTA: Canada pushes for enforceable, progressive labour standards. Maclean's" The Canadian Press. (Septiembre 26 2017). https://www.macleans.ca/economy/ nafta-canada-pushes-for-enforceable-progressive-labour-standards/. (Consultado el 22-2-2020). 
Castellanos Elías, Julio. Sueldos y salarios de la industria automotriz en México en 2003 y 2008. 2012: http://congreso.investiga.fca.unam.mx/docs/xvii/docs/H04.pdf (Consultado el 8-6-2020).

Covarrubias, Alex. "Mexico competitive advantage in NAFTA: A case of social dumping?". Norteamérica Revista Académica del CISAN-UNAM, 14(2019). http://dx.doi.org/10.22201/ cisan.24487228e.2019.1.340. (Consultado el 2-6-2020).

Fetscherin, S. M. y. M. "A Double Diamond Comparison of the Automotive Industry of China, India, and South Korea”. Competition Forum Rollins College, 7(1): 6-16.

Foundation, T. H., Index of Economic Freedom. https://www.heritage.org/index/ranking (Consultado el 25 de febrero de 2020). González, Lilia "Incrementos al salario mínimo deben ir acompañados de productividad: CEESP” El Financiero. (29 de septiembre de 2019), https://www.eleconomista.com.mx/ empresas/Incrementos-al-salario-minimo-deben-ir-acompanados-de-productividad-CEESP-20190929-0014.html (Consultado el 3-3-2020).

INEGI, Colección de Estudios Sectoriales y Regionales. http:// internet.contenidos.inegi.org.mx/contenidos/Productos/ prod_serv/contenidos/espanol/bvinegi/productos/nueva_estruc/702825106829.pdf. (Consultado el 6 de febrero de 2020).

Krugman, Paul y Obstfeld, Maurice. Economía Internacional Teoría y Política. Estados Unidos: Pearson, 2006.

Linares Zarco, Jaime. "El espacio de los salarios y de los robots en la industria automotriz en México". En: Dinámica Económica y Procesos de Innovación en el Desarrollo Regional. México: Asociación Mexicana de Ciencias para el Desarrollo Regional A.C y UNAM, 2018, 168- 189.

Miller, T. A. K., "Defining Economic Freedom”. T. H. Foundation, ed.Index of Economic Freedom. Washington D.C.: s.n., 21-25.

Morales, Roberto. "México escala al cuarto sitio en exportación de autos". ElEconomista. 26 de marzo de 2019), https://www.eleconomista.com.mx/empresas/Mexico-escala-al-cuarto-sitio-en-exportacion-de-autos-20190326-0158.html (25-2-2020). 
Notimex. Economiahoy.mx. Notimex, 2017, https://www.economiahoy.mx/empresas-eAm-mexico/noticias/9299538/07/18/ Digitalizacion-impulsa-25-productividad-de-la-industria-automotriz.html (Consultado el 26 de marzo de 2020).

OCDE. Labour productivity forecast. OCDE. https://data.oecd. org/lprdty/labour-productivity-forecast.htm\#indicator-chart (Consultado el 26 de febrero de 2020).

Ochoa Valladolid, Karen, "México y la cuena del Pacífico". Análisis. La industria automotriz de México: las expectativas de competitividad del sector de autopartes, No. 26: (2005): 33-58.

Posadzki, Alexandra and Loriggio, Paola. General Motors moving more than 600 jobs in Ontario to Mexico for cheaper labour: union. https://globalnews.ca/news/3209728/general-motorsto-cut-up-to-600-jobs-in-southwestern-ontario/ (Consulado el 26 de febrero de 2020).

Ruckelshaus, Catherine, Catherine Ruckelshaus. "Manufacturing low pay: declining wages in the Jobs that built America's Middle Class", National Employment Law Project, (20 noviembre 2014). https://www.nelp.org/publication/manufacturing-low-pay-declining-wages-in-the-jobs-that-built-americas-middle-class/ (Consultado el 25-2-2020).

Swiecki, B. y. D. M., Center for Automotive Research. The Growing Role of Mexico in the North American Automotive Industry. Ann Arbor: Center for Automotive Research, 2016.

Tyndall, Gene, Christopher Gopal, Wolfgang Partsch, and John Kamauff. "Supercharging Supply Chains: New Ways to Increase Value Through Global Operational Excellence", Nueva York: John Wiley \& Sons, 1998.

UNCTAD. "Global Investment Trends and Prospects". Chapter 1. Nueva York: United Nations Conference for Trade and Development, 2018.

UNESCO, How much does your country invest in R\&D. http:// uis.unesco.org/apps/visualisations/research-and-development-spending/ (Consultado el 25 de febrero de 2020).

Vicencio Miranda, A. La industria automotriz en México. Antecedentes, situación actual y perspectivas. http://www.scielo.org.mx/scie- 
104 Los SALARIos En MÉxico COMO FACTOR DE COMPETENCIA DESLEAL EN LA INDUSTRia AUtomotriz, 2003-2019 / Agustin Tapia Alba, Cesaire Chiatchoua

lo.php?script=sci_arttext\&pid=S0186-10422007000100010 (consultado el 27 de febrero de 2020).

World Bank. Foreign direct investment, net outflows (BoP, current US\$), https://data.worldbank.org/indicator/BM.KLT. DINV.CD.WD (Consultado el 25 de febrero de 2020).

World Economic Forum, The Global Competitiveness Report 2019, Ginebra: Klaus Schwab. 